The penetrative and burning powers of liquid vesicant drops through various types and conditions of clothing were also investigated. Different sizes of drops were used, and they were dropped from a height on to the clothed subject and at a terminal velocity corresponding to that of spray. From the results of these experiments calculations were made to estimate the degree of vesicant contamination required to make a soldier a casualty. The validity of these calculations was checked by direct exposure of soldier volunteers to vesicant spray in the field (see Fig. 2).

A somewhat similar problem was presented by the request to determine the burning power of phosphorus through various types of clothing. Here known quantities of burning phosphorus were dropped from a height on to clothed volunteers. (The phosphorus was supported on a 1-amp. fuse wire which, on passage of an electric current, ignited the phosphorus and allowed it to fall.) Calculations similar to the vesicant calculations were then made. The relation between vesicant-vapour dosage and reversible eye-damage was also determined, chiefly by means of a constant-flow method through an eye-mask.

\section{Defendive Tests}

The above offensive tests were a necessary preliminary to experiments designed to evaluate protective measures and equipment; the possible hazards had first to be determined before methods of defence could be formulated. Thus the methods used in assessing the value of protective devices were very similar to those already described. For example, vesicant injuries to the eye were produced and treated with various therapies. Decontaminating ointments, creams, powders, and solutions were tested on the contaminated skin of volunteers. Protective clothing and impregnated clothing were assessed on subjects exposed to vesicant vapour dispersed in the gaschamber or in the field and in concentrations known to be normally damaging. The hazards presented by traversing or occupying contaminated ground, and methods of reducing them, were also determined, while the effect on military efficiency of wearing various types of respirators was measured by the use of fully trained soldier personnel.

Of course the experience gained by these large-scale experiments on human subjects was often utilized for non-chemicalwarfare problems. Thus, to quote a few examples, the problem of facepiece and rubber dermatitis, the question of irritability of garments heavily impregnated with D.D.T., and an attempt to determine the factors involved in the production of khaki or textile dermatitis were typical commitments.

I wish to thank the Chief Scientific Officer, Ministry of Supply, for permission to pubiish this paper. I must also pay tribute to Surg. Capt. A. Fairley, R.N.(ret.). for long a lone pioneer in this work on human volunteers; to Lieut.-Col. S. Curwen R.A.M.C.; and to many other colleagues at Porton whose work II have freely quoted. Finally, my sincerest thanks to, and admiration for, the host of volunteers who made all this work possible.

\section{Medical Memoranda}

\section{Removal of Large Ovarian Tumour Complicated by Cardiac Failure}

The interest in the following case lies in the size of the tumour removed and the remarkably rapid recovery of a failing heart as soon as the pressure thereon was eased.

\section{CASE Report}

Early in 1946 an African village woman, aged about 50 and of average stature, was admitted to hospital at Winneba. She stated that she had suffered increasing abdominal girth for three years. She was found to be very thin, dyspnoeic, and slightly cyanotic. The cervical veins were fuil. Cardiac dullness was increased to the right Cardiac rhythm was regular, rate 90 a minute at rest. The interval between the first and second apical sounds was increased. Both lower limbs were oedematous. The abdomen was grossly distended. Abdominal and pelvic examination revea'ed the presence of a smooth, firm tumour which appeared to fiil the pelvis and abdominal cavity completely. Its upper limit could not be defined. The uterus and rectum were prolapsed. After a week's rest in bed her general condition improved slightly, and operation was decided upon.
Under open anaesthesia (3:2 ether-chloroform mixture) laparotomy was performed through a long right paramedian incision. This revealed a smooth, white glistening tumour, areas of which were fluctuant, extending well down into the pelvis, where its pedicle could be felt on the right side. Laterally the tumour spread outwards into the flanks, and above was pressing on the liver. Fortunately the gut was not adherent to it. With considerable difficulty, owing to its size, the tumour was withdrawn from within the peritoneal cavity; the pedicle was clamped, the mass removed in one piece, and the the pedicle was clamped, the mass removed in one piece, and the abdomen closed. Camphor in oil had been given intramusculariy the pulse became feeble and irregular.

Examination of the tumour showed it to be a typical pseudomucinous cystadenoma of the ovary. The proportion cyst to solid was approximately two to three. The tumour weighed $41 \mathrm{lb}$. (18.6 kg.). After operation the patient made a rapid and uneventful recovery. She left hospital one month later in good health.

I am indebted to the Director of Medical Services, Gold Coast, for permission to publish this report.

Colonial Medical Service, Gold Coast.

\section{A. F. Fowler,}

Medical Officer.

\section{Helminths Infective to Man in the Syrian Hamster}

The Syrian hamster (Cricetus auratus), which is susceptible to several human diseases (e.g., leishmaniasis, tuberculosis, Weil's disease, etc.), is being increasingly used, both in this country and in America, as a laboratory animal. In a recent note Stunkard (1945) recorded the finding of the eggs of the dwarf tapeworm, Hymenolepis nana, in the faeces of a batch of these animals purchased for experimental purposes. Since this species is directly infective to man, requiring no intermediate host, that author stressed the risk of infection being acquired by laboratory workers, animal-house attendants, and others handling the animals. $H$. nana commonly occurs in rats and mice, and several workers (Saeki, 1920; Uchimura, 1922; Kiribayashi, 1933) have succeeded in infecting man with eggs from murine sources; hence there is ground for the belief expressed by Chandler (1922) and Faust (1939) that human infection may be acquired from eggs derived from rodents. Once acquired, human infection with $H$. nana may later reach ser:ous proportions by reason of internal auto-infection (Hunninen, 1935).

In recent months a number of hamsters which had been used for experimental infections of kala-azar in these laboratories have been examined post mortem for helminth parasites. Out of a total of 160 animals, $19(11.9 \%)$ were found to harbour $H$. nana, some being fairly heavily infected. One specimen yielded no fewer than 22 adult worms. Since most of these infected individuals belonged to one batch there is a possibility of a much higher incidence in other cases. Further, 83 animals $(51.9 \%)$ were infected, some very heavily, with the oxyurid nematode Syphacia obvelata. This species is also believed to be infective to man, a case of human infection having been reported from an American child in the Philippines (Riley, 1919). Several more recent cases of $S$. obvelata infection have, however, proved to be spurious (Craig and Faust, 1945).

In view of the possibility of human infection with these worms having been acquired by contamination from the faeces of these infected hamsters, it was deemed advisable to make an examination of all personnel involved in handling the animals. Accordingly, two stool samples and seven N.I.H. swabs* at daily intervals were taken from the four individuals in question and examined respectively for the eggs of $H$. nana and $S$. obvelata. All were negative.

Hence, despite the fact that human infection with these helminth species does undoubtedly occur, and in view of the fact that no special precautions were taken in handling the hamsters, the risk of infection to laboratory workers and animalhouse attendants does not, in practice, appear to be a serious one.

John M. Watson, A.R.C.S

Helminthologist to the Wellcome Laboratories of Tropical Medicine, London.

REFERENCES

Chandler, A. C. (1922), J. Amer. med. Ass., 78, 636.

Craig, C. F., and Faust, E. C. (1945). Clinical Parasitology, 4th ed. H. Kimpton,

London. (1939). Human Helminthology, 2nd ed. H. Kimpton, London.
Faust, E. C.

Faust, E. C. (1939). Human Helminthology, 2nd ed.

Hunninen, A. v. (1935). Amer. J. Hyg., 22, 414.

Kiribayashi, S. (1933). Taiwan Igakkai Zas

Riley, W. A. (1919). J. Parasitol., 6, 89.

Saeki, T. (1920). "Experimental Studies on the Development of Hymenolepis nana." Abstract in Trop. Dis. Bull., 1921, 18, 112.

Stunkard, H. W. (1945). J. Parasitol., 31, 151.

Uchimura, R. (1922). On the Development of Hymenolepis nana and Hymenolepis murina." Abstract in Trop. Dis. Bull., 1923, 20. 626.

* The National Institute of Health " cellophane" swab devised by Hall (1937) for the diagnosis of oxyuriasis. 